\title{
Classification of Northern Hemisphere stratospheric ozone and water vapor profiles by meteorological regime
}

\author{
M. B. Follette-Cook ${ }^{1, *}$, R. D. Hudson ${ }^{2}$, and G. E. Nedoluha ${ }^{1}$ \\ ${ }^{1}$ Naval Research Lab, Remote Sensing Division, Washington, D.C., 20375, USA \\ ${ }^{2}$ Department of Atmospheric and Oceanic Science, University of Maryland, College Park, MD 20742, USA \\ * currently at: Goddard Earth Sciences and Technology Center, University of Maryland, Baltimore County, MD 20771, USA
}

Received: 7 May 2008 - Published in Atmos. Chem. Phys. Discuss.: 15 July 2008

Revised: 18 April 2009 - Accepted: 29 July 2009 - Published: 20 August 2009

\begin{abstract}
The subtropical and polar upper troposphere fronts and the polar vortex serve as the boundaries to divide the Northern Hemisphere into four meteorological regimes. These regimes are defined as (1) the arctic regime - within the polar vortex, (2) the polar regime - between the polar front and the polar vortex, or when the latter is not present, the pole, (3) the midlatitude regime - between the subtropical and polar fronts, and (4) the tropical regime - between the equator and the subtropical front.

Data from the Halogen Occultation Experiment (HALOE) and the Stratospheric Aerosol and Gas Experiment II (SAGE II) were used to show that within each meteorological regime, ozone and water profiles are characterized by unique ozonepause and hygropause heights. Daily measurements and seven-year (1997-2003) monthly climatologies showed that, within each meteorological regime, both constituents exhibited distinct profile shapes from the tropopause up to approximately $20 \mathrm{~km}$. This distinction was most pronounced in the winter and spring months, and weak in the summer and fall. Despite differences in retrieval techniques and sampling between the SAGE and HALOE instruments, the seven-year monthly climatologies calculated for each regime agreed well for both species below $\sim 22 \mathrm{~km}$.

Given that profiles of ozone and water vapor exhibit unique profiles shapes within each regime in the UTLS, trends in this region will therefore be the result of both changes within each meteorological regime, and changes in the relative contribution of each regime to a given zonal band over time.
\end{abstract}

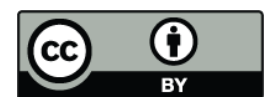

Correspondence to: M. B. Follette-Cook (melanie.cook@nasa.gov)

\section{Introduction}

Understanding the distributions of ozone and water vapor are essential for determining the radiative and chemical budgets of the atmosphere. In the lower stratosphere, ozone and water vapor are good dynamical tracers, owing to their long chemical lifetimes (Brasseur and Solomon, 1984), and gradients across the tropopause. However, the extratropical upper troposphere/lower stratosphere (UTLS) region is characterized by complex interactions between dynamics, chemistry, microphysics, and radiation.

Previous studies have broken the stratosphere into several components. The "overworld" is the region entirely within the stratosphere, the bottom of which is the $380 \mathrm{~K}$ potential temperature surface (Hoskins, 1991; Holton et al., 1995). In the lowest part of the overworld, the "lower transport regime" or "tropically controlled transition region" extends up to $450 \mathrm{~K}$ in the tropics (Hitchman et al., 1994; Rosenlof et al., 1997). This region is a transition between the nonlocally controlled middle atmosphere and the synoptically influenced "middleworld". The lowest component of the stratosphere is often referred to as the "lowermost stratosphere" (LMS) or the stratospheric part of the middleworld (Hoskins, 1991; Holton et al., 1995).

Tropospheric air enters the stratosphere through two main pathways. The first is cross isentropic transport through the tropical tropopause. Once in the stratosphere, air is either quasi-horizontally propagated poleward (Rosenlof et al., 1997; Randel et al., 2001) or continues to rise via the ascending branch of the Brewer Dobson circulation (Brewer, 1949). The second pathway is stratosphere-troposphere exchange (STE) on isentropic surfaces (Dessler et al., 1995; Holton et al., 1995; Chen, 1995).

In this paper we will use the concept of meteorological regimes as defined by Hudson et al. $(2003,2006)$ to examine

Published by Copernicus Publications on behalf of the European Geosciences Union. 
ozone and water vapor profiles from the Halogen Occultation Experiment (HALOE) and the Stratospheric Aerosol and Gas Experiment II (SAGE II) within each regime. Uniquely, this method requires only the measurement of ozone columns in order to classify dynamically distinct regions. The method takes advantage of the sudden change in tropopause height which occurs across the subtropical and polar upper troposphere fronts. More specifically, as the front is crossed from the equatorward side to the poleward side, there will be a decrease in tropopause height (Bluestein, 1993). This has been widely observed and reported in the literature (Reed, 1955; Defant and Taba, 1957; Danielsen, 1968; Shapiro, 1978, 1980, 1985; Pan et al., 2004). The regions surrounding these fronts will therefore be associated with gradients in tropopause height. Further, the regions away from the fronts will be characterized by relatively little variation in tropopause height (Defant and Taba, 1957; Hudson et al., 2003).

Approximately ninety percent of the total ozone column is located in the stratosphere, and the mid to upper stratosphere is in photochemical equilibrium (Brasseur and Solomon, 1984). Therefore, day-to-day changes in total ozone are dominated by how much ozone is in the mid to lower stratosphere, which is in turn influenced by the height of the tropopause. This relationship between tropopause height and total ozone has been observed in previous studies (Schubert and Munteanu, 1988; Petzoldt et al., 1994; Hoinka et al., 1996; Steinbrecht et al., 1998; Varotsos et al., 2004).

Considering that the subtropical and polar fronts are characterized by changes in tropopause height, and changes in total ozone are correlated with changes in tropopause height, then it follows that the fronts are regions of total ozone gradient (Dobson, 1929; Shalamyanskiy and Romanshkina, 1980; Shapiro et al., 1982; Karol et al., 1987). Hudson et al. (2003) found that these fronts, along with the polar vortex, divided the Northern Hemisphere total ozone field into meteorological regimes, which they defined as (1) the arctic regime - within the polar vortex, (2) the polar regime between the polar front and the polar vortex, or when the latter is not present, the pole, (3) the midlatitude regime between the subtropical and polar fronts, and (4) the tropical regime -between the equator and the subtropical front. They used data from the TOMS instruments, rawinsondes, and ozonesondes to show qualitatively, that each regime had distinct values of total ozone, tropopause height, and ozonepause height (Hudson et al., 2003, 2006) for the month of March.

The method used here is but one of many methods which are used to remove the effects of short timescale dynamical variability on tracers in the UTLS. Tropopause heightreferenced coordinates and tracer-tracer correlations have been used to show that an extratropical tropopause layer (ExTL) exists just above the extratropical tropopause, poleward of the subtropical front (Logan, 1999; Fischer et al., 2000; Hoor et al., 2002; Pan et al., 2004; Hegglin et al., 2006;
Randel et al., 2007). This mixing layer is a result of two-way (STE) across the tropopause, and has characteristics of both tropospheric and stratospheric air (Pan et al., 2004). Like tropopause height-referenced coordinates, the meteorological regime method removes the effects of tropopause level changes from measurements. However, because it identifies barriers to mixing, it will also help to distinguish between measurements on different sides (i.e. in different regimes), that may have similar heights above the tropopause.

Potential vorticity (PV), equivalent latitude, and tracer equivalent latitude are also useful coordinates for analyses. Assuming adiabatic and frictionless flow, PV is conserved along the trajectory of a parcel (Hoskins et al., 1985; Shapiro, 1980) making it a good dynamical coordinate. The equivalent latitude of a potential vorticity (PV) contour is the latitude of a circle, centered about the pole, enclosing the same area as the PV contour (Butchart and Remsberg, 1986). Tracer equivalent latitude applies the same concept to tracer isopleths using a "global isentropic advection simulation" (Allen and Nakamura, 2003). These methods use results from meteorological models, whereas the regime method uses only column ozone measurements. Thus, the meteorological regime method has the advantage of being a directly measured quantity, but the disadvantage of not providing level-by-level information. Unlike PV and equivalent latitude, the meteorological regime method provides a coarse classification into three regions, but because the boundaries dividing these regions are based upon physical boundaries to mixing, they encompass relatively homogenous air masses. This classification is advantageous when working with a limited number of measurements, since it allows for the binning together of measurements covering a large range of equivalent latitudes.

While, by definition, the total ozone column is different within each of these regimes, the motivation here is to determine how well, and over what altitude ranges and seasons, stratospheric ozone and water vapor profiles can be usefully classified by such meteorological regimes. A brief description of the data used follows in Sect. 2. Section 3 provides an explanation of the method used to classify the profiles into meteorological regimes. Sections 4 and 5 will show the results of the ozone and water vapor analyses, respectively. The summary and discussion will follow in Sect. 6.

\section{Data}

\subsection{HALOE}

Data from the HALOE instrument has been widely used to study the chemistry of the stratosphere because of its near global coverage, its coincident measurements of several key chemical species, and its long measurement record (11 October 1991-21 November 2005). HALOE was a limb-scanning solar occultation instrument with a vertical resolution of 
about $2.3 \mathrm{~km}$, and a horizontal resolution of $\sim 200 \mathrm{~km}$ (Russell et al., 1993; Kley et al., 2000). The satellite orbit precessed, covering from $\sim 80^{\circ} \mathrm{N}-80^{\circ} \mathrm{S}$ over a year. The maximum sampling for each day was 15 sunrise and 15 sunset measurements.

Validations have been done on the various versions of the HALOE ozone data (Brühl et al., 1996; Bhatt et al., 1999). The HALOE version 19 level 3 data has been used here. This data has also been screened for cirrus cloud contamination using the method described in Hervig and McHugh (1999). The sunrise and sunset data have been combined and show differences less than $5 \%$ above $100 \mathrm{mb}$ (Brühl et al., 1996). Bhatt et al. (1999) found agreement with coincident ozonesonde measurements better than $10 \%$ down to $200 \mathrm{mb}$, and better than $20 \%$ down to $300 \mathrm{mb}$ in the extratropics.

For water vapor profiles, the combined systematic and random errors in the lower stratosphere are 14-24\% (Grooß and Russell, 2006). Kley et al. (2000) performed an extensive validation, and found that HALOE v19 water vapor profiles agreed with correlative measurements within $\sim 10 \%$ throughout most of the stratosphere. Differences increase somewhat in the upper stratosphere and near the tropopause.

\subsection{SAGE II}

The SAGE II instrument was launched on board the Earth Radiation Budget Satellite (ERBS), and was operational from 5 October 1984 to 26 August 2005. SAGE II (hereafter referred to as SAGE) was a seven-channel sun photometer that used solar occultation to infer vertical profiles of ozone, water vapor, $\mathrm{NO}_{2}$, and aerosol extinction at several wavelengths from $0.385-1.02 \mu \mathrm{m}$. Similar to HALOE, SAGE covered from $\sim 70^{\circ} \mathrm{S}$ to $\sim 70^{\circ} \mathrm{N}$, and made a maximum of 15 sunrise and 15 sunset measurements per day (Cunnold et al., 1989). The vertical resolution was $1 \mathrm{~km}$ (Chu et al., 1989), and the horizontal extent along the line of sight was $200 \mathrm{~km}$ by $2.5 \mathrm{~km}$ for a $1-\mathrm{km}$ retrieved layer (WMO, 1998).

For SAGE ozone profiles, the dominant source of error is the measurement error, but the total random error for a $1-\mathrm{km}$ vertical resolution is less than $7 \%$ between $2 \mathrm{~km}$ above the tropopause and $43 \mathrm{~km}$ (Cunnold et al., 1989). Better than $10 \%$ agreement between SAGE version 6.1 ozone measurements and coincident ozonesonde measurements was found down to the tropopause (Wang et al., 2002). Version 6.2 of the SAGE data is used in this paper.

Version 6.2 SAGE water vapor profiles, though still affected by the presence of aerosols, have reduced sensitivity with respect to previous versions. The retrievals were modified to remove the dry bias with respect to the HALOE water vapor profiles (Thomason et al., 2004). When SAGE water vapor profiles were compared with both ground-based and satellite correlative measurements, good agreement of within $10 \%$ was seen from $15-40 \mathrm{~km}$. Comparison between data sets in the region of the hygropause is difficult, given the increase in atmospheric variability and differences in the tech- niques and ability of each platform in resolving this region. However, SAGE comparisons with balloon-borne frost-point hygrometers and MkIV interferometers showed agreement around the hygropause to within 10\% (Taha et al., 2004).

\section{Method}

The Total Ozone Mapping Spectrometer (TOMS) instruments measured backscattered solar ultraviolet (UV) radiation and provided daily high-resolution global maps of total ozone. Earth Probe (EP) TOMS made measurements from July 1996-December 2005. This paper uses the level-3 version $8 \mathrm{EP}$ TOMS total ozone data on a $1^{\circ}$ latitude by $1.25^{\circ}$ longitude grid.

As explained in the introduction, Hudson et al. (2003, 2006) utilize gradients in the total ozone field to locate the positions of the subtropical and polar fronts. This method was able to track a net northward movement of the subtropical front that has now been observed in various datasets (Hudson et al., 2006; Fu et al., 2006; Hu and Fu, 2007; Seidel and Randel, 2007; Archer and Caldeira, 2008). Starting with daily climatological values of total ozone for each front, the total ozone within each regime is calculated and used to compute new values that represent each front, which vary with day and latitude. The method is repeated until the area of each regime changes less than 5\%. Detailed descriptions of the procedures used can be found in Hudson et al. (2003, 2006). While the subtropical and polar fronts are calculated based on total ozone gradients, the polar vortex boundary is determined from the position of the sharpest gradient in $\mathrm{PV}$ on the $550 \mathrm{~K}$ potential temperature surface. For each HALOE and SAGE profile, the TOMS ozone column measurements for that day were used to classify the profile into a particular meteorological regime. Profiles that fell within a boundary region are not included in the analysis. In the present work we have widened the boundary by one pixel in latitude and longitude, resulting in a boundary region an average of three pixels ( $3^{\circ}$ latitude by $3.75^{\circ}$ longitude) thick. Because EP TOMS measurements are made at approximately 11 a.m., whereas both SAGE and HALOE measurements are made at local sunrise or sunset, there exists the possibility that shifts in the fronts may result in the misclassification of some SAGE and HALOE profiles. This source of error will depend on the time of year, as weather patterns are more persistent in summer and fall.

Ozone profiles from SAGE and HALOE, from $25^{\circ}-60^{\circ} \mathrm{N}$, were classified into meteorological regimes for every day that there were both profile measurements and EP TOMS data available between January 1997 and December 2003. Ozonepause and hygropause heights were also determined for every HALOE profile. The sharp increase in ozone from the troposphere to the stratosphere can be used to find the position of the "chemical tropopause" or "ozonepause". Bethan 


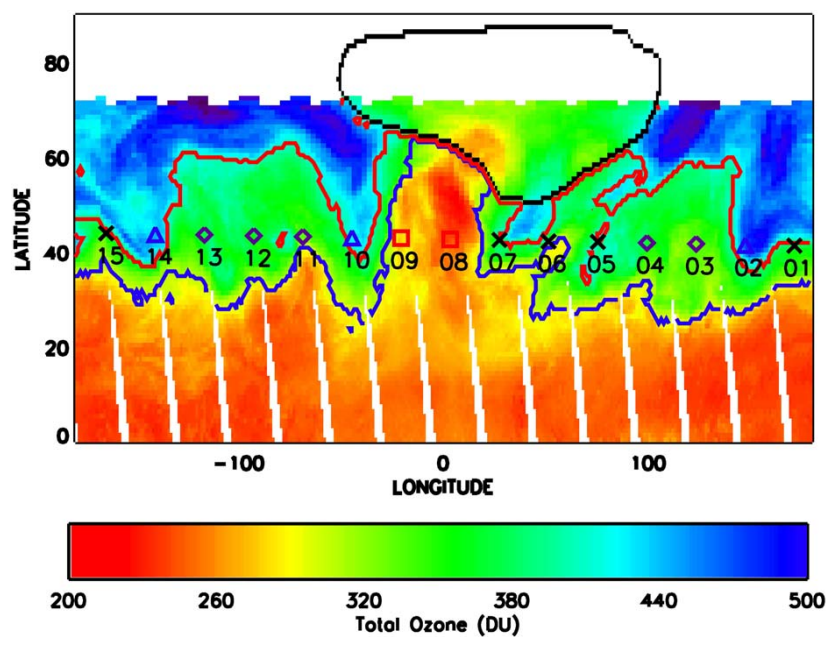

Fig. 1. EP TOMS total ozone field for 18 February 1998. The subtropical, polar, and arctic boundaries are shown as blue, red, and black lines, respectively. Each symbol represents a HALOE sunset measurement for this day, and has been numbered 01 through 15 . The color and choice of each symbol corresponds to its classification: red squares - tropical, purple diamonds - midlatitude, blue triangles - polar, and black X's - boundary.

et al. (1996) defined an ozonepause based on the lowest altitude where the ozone profile met the following three criteria,

- The vertical gradient in ozone mixing ratio exceeds $60 \mathrm{ppbv} \mathrm{km}^{-1}$ over a depth of approximately $200 \mathrm{~m}$

- The ozone mixing ratio is greater than $80 \mathrm{ppbv}$

- The ozone mixing ratio immediately above the tropopause is greater than $110 \mathrm{ppbv}$

They found that the ozonepause and lapse-rate tropopause altitudes calculated from 628 high latitude ozonesondes differed by an average of $1 \mathrm{~km}$. We have adopted the Bethan et al. (1996) definition for this paper. Because the HALOE data become noisy near and below the ozonepause (Bhatt et al., 1999; Grooß and Russell, 2005), an additional criterion requiring the vertical gradient $2 \mathrm{~km}$ above the ozonepause to be positive was added. This will also filter out most stratospheric intrusions into the troposphere. However, the "higher" ozonepause will be the one most relevant to this work, as it is the one that will have the greatest effect on the column. In order to test how the criteria used were affected by the smoothing performed in a typical retrieval algorithm, ozonesonde data from Wallops Island, VA were analyzed from 1996 through 2002. Ozonepause heights calculated using the high resolution ozonesonde data were compared with those calculated after a $2 \mathrm{~km}$ boxcar smoothing had been applied to the data. Over the seven year period, 396 profiles were analyzed, and the mean difference (sonde height - smoothed height) was $\sim 500 \mathrm{~m}$. The hygropause was defined as the altitude of the water vapor minimum (Kley et al., 1979).

\section{Ozone profile classification}

\subsection{One day}

Hudson et al. (2003) showed that when Northern Hemisphere rawinsonde and ozonesonde data were divided into meteorological regimes, similar profile shapes were seen within each regime. Figure 1 shows the EP TOMS total ozone field for 18 February 1998 in addition to the subtropical, polar, and polar vortex boundaries, shown as blue, red, and black lines, respectively. Each symbol on this figure represents a sunset HALOE event for this day, and has been assigned a number from 01 through 15 . The HALOE measurements are approximately 24 degrees of longitude apart. The color and choice of symbol corresponds to its classification: blue triangles polar; purple diamonds - midlatitude; red squares - tropical; black X's - boundary. HALOE profiles are present in all three regimes on this day, in addition to several boundaryclassified profiles that have been eliminated. In order to examine these profiles closely, Fig. $2 \mathrm{a}-\mathrm{c}$ shows the individual profiles that have been classified as polar, midlatitude, and tropical, respectively. The polar profiles in Fig. 2a have very similar profile shapes and ozonepause heights, $7-8.5 \mathrm{~km}$, despite being very far apart in longitude. The two tropical profiles in Fig. 2c also have similar shapes and show ozonepause heights at around $16-17 \mathrm{~km}$. Figure $2 \mathrm{~b}$ shows five midlatitude ozone profiles. These too also show similar profile shapes, however their ozonepause heights range from 10 to approximately $15 \mathrm{~km}$, a much larger range than in the polar or tropical regimes. As mentioned in the introduction, the region poleward of the subtropical front (the ExTL) has been observed to have tropospheric and stratospheric characteristics, as well as frequent occurrence of double thermal tropopauses (Fischer et al., 2000; Hoor et al., 2002; Pan et al., 2004; Randel et al., 2007). These factors could be contributing to the higher variability around the midlatitude regime ozonepause and LMS.

This day shows the utility of classifying profiles by meteorological regime. All of the HALOE measurements seen in Fig. 2 are located within $\sim 4$ degrees latitude of each other, as all of them fall between approximately $41^{\circ}$ and $44^{\circ} \mathrm{N}$, yet they show distinctly different ozonepause heights. As an example, at $13 \mathrm{~km}$, a zonal average over this very small latitude band would contain both upper tropospheric and lower stratospheric air. If, however, the profiles are classified by regime, then the ozone profiles indicate that in the tropical regime air at this altitude is tropospheric, while in the polar regime, air at these altitudes is clearly stratospheric. 

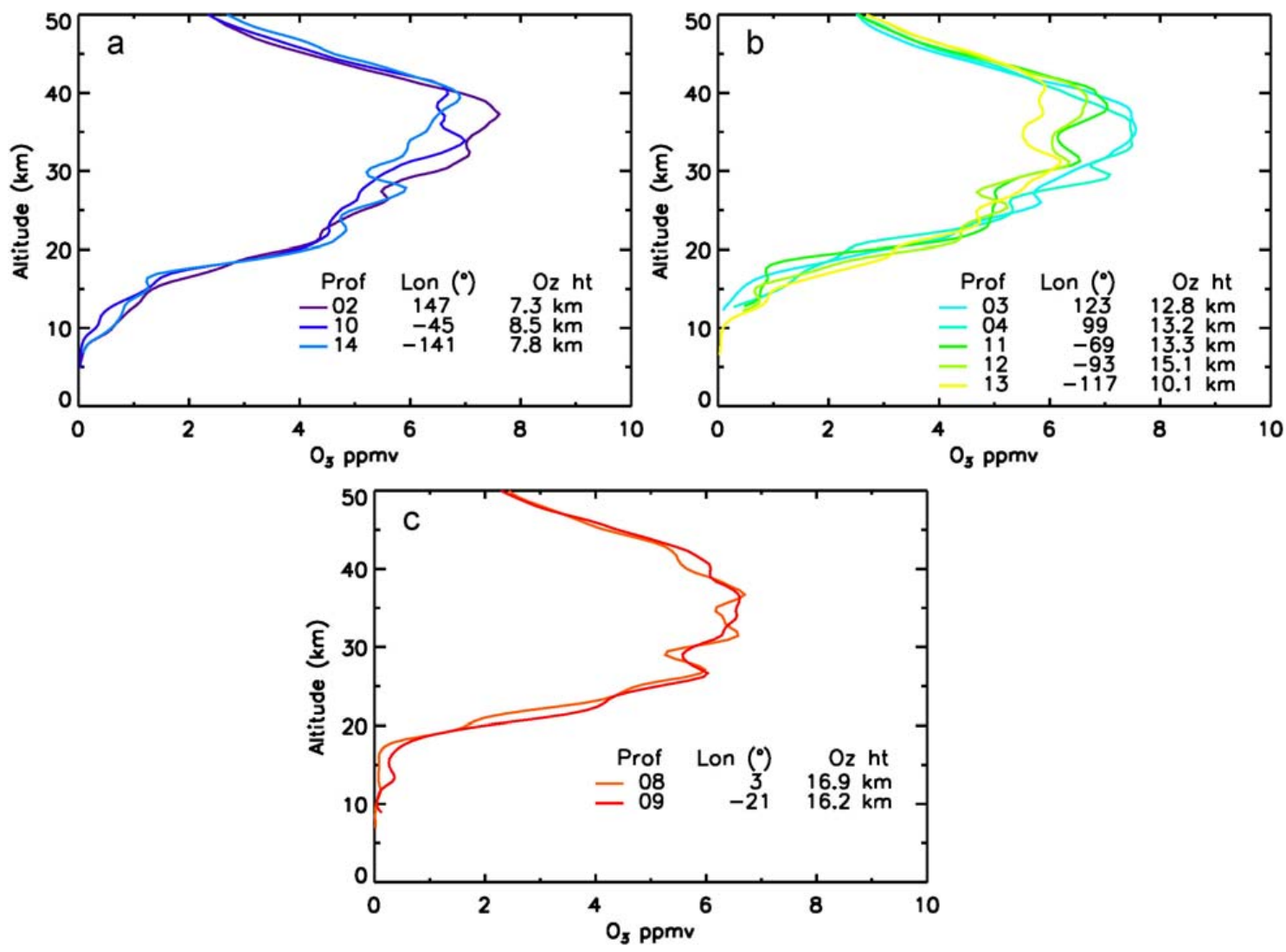

Fig. 2. HALOE ozone profiles that correspond to the colored symbols on Fig. 1 for 18 February 1998 for the (a) polar regime, (b) midlatitude regime, and (c) tropical regime. The profile numbers, longitudes, and ozonepause heights are also listed.

\subsection{Climatology}

Data from both HALOE and SAGE were used to calculate monthly climatologies for each regime over the time period 1997-2004 between $25^{\circ}$ and $60^{\circ} \mathrm{N}$. Figure $3 \mathrm{a}$ and $\mathrm{b}$ shows the March and September ozone profile climatologies, respectively, calculated using data from the HALOE instrument for the subtropical (red), midlatitude (green), and polar (blue) regimes. The standard deviation $(1 \sigma)$ is shown as dashed lines on either side of the mean profile, and the number of points used is shown on the right, in each plot. Due to the nature of HALOE's orbit, some months had limited sampling in certain regimes. If the number of profiles available for a regime was below 20, the mean was not included.

In the lower stratosphere in March, the climatological profiles show distinct profile shapes in the LMS within each regime. However, the tropical and midlatitude means are nearly indistinguishable in September. When the ozone values $3 \mathrm{~km}$ above the ozonepause are examined, the tropical regime displays values $\sim 0.25$ ppmv higher than the polar in winter, and $\sim 0.5$ ppmv higher in summer. The midlatitude values fall in between the tropical and polar. This indicates that ozone values increase with altitude faster in the tropi- cal regime than in the midlatitude or polar regimes. In order to quantify the chemical distinction seen between the regime climatologies, Eq. (2) from Sparling (2000) was used to calculate their measure, $\delta$, as a function of altitude. $\delta$ is calculated as follows:

$\delta \equiv\left|\tilde{\chi}_{t}-\tilde{\chi}_{m}\right| /\left(\sigma_{t}+\sigma_{m}\right)$

where $\tilde{\chi}_{t}, \tilde{\chi}_{m}$, and $\sigma_{t}, \sigma_{m}$ are the modes and standard deviations, respectively of the tropical and midlatitude regime. Figure $4 \mathrm{a}$ and $\mathrm{b}$ shows time-altitude contour plots of $\delta$ for the tropical and midlatitude, and midlatitude and polar regimes, respectively. Contours are drawn at 0.25 intervals, beginning with 0.50 . A minimum of six data points within the mode of a regime was required to calculate $\delta$ at a given altitude. The grey hatched areas indicate months where there were more than $40 \%$ non-zero $\delta$ values below $50 \mathrm{~km}$. Sparling (2000) defines chemical distinction in tracer $\chi$ where $\delta>1$. In Fig. $4 \mathrm{a}$ and $\mathrm{b}$, in general, higher $\delta$ values $(\delta>0.75)$ are found from $\sim 10-20 \mathrm{~km}$ from November through March. Values of $\delta>0.75$ are only sparsely observed above $\sim 22 \mathrm{~km}$. The $\sim 10-20 \mathrm{~km}$ altitude range is where one would expect to find a large meteorological influence on stratospheric ozone profiles (Logan, 1999; Koch et al., 2002; Newchurch et al., 

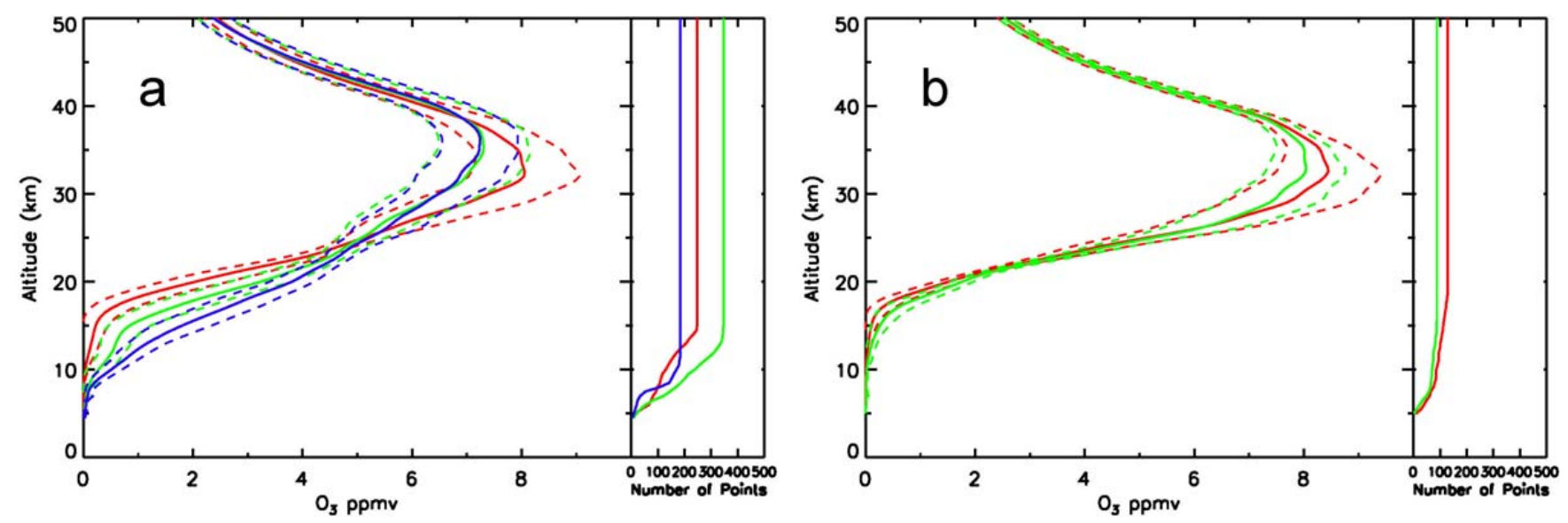

Fig. 3. HALOE ozone profile climatologies calculated from 1997-2004 between $25^{\circ}$ and $60^{\circ} \mathrm{N}$ for (a) March and (b) September. The one-sigma standard deviations of the mean are shown as dashed lines, and the number of points is shown on the right. The color scheme is: red - tropical, green - midlatitude, and blue - polar.
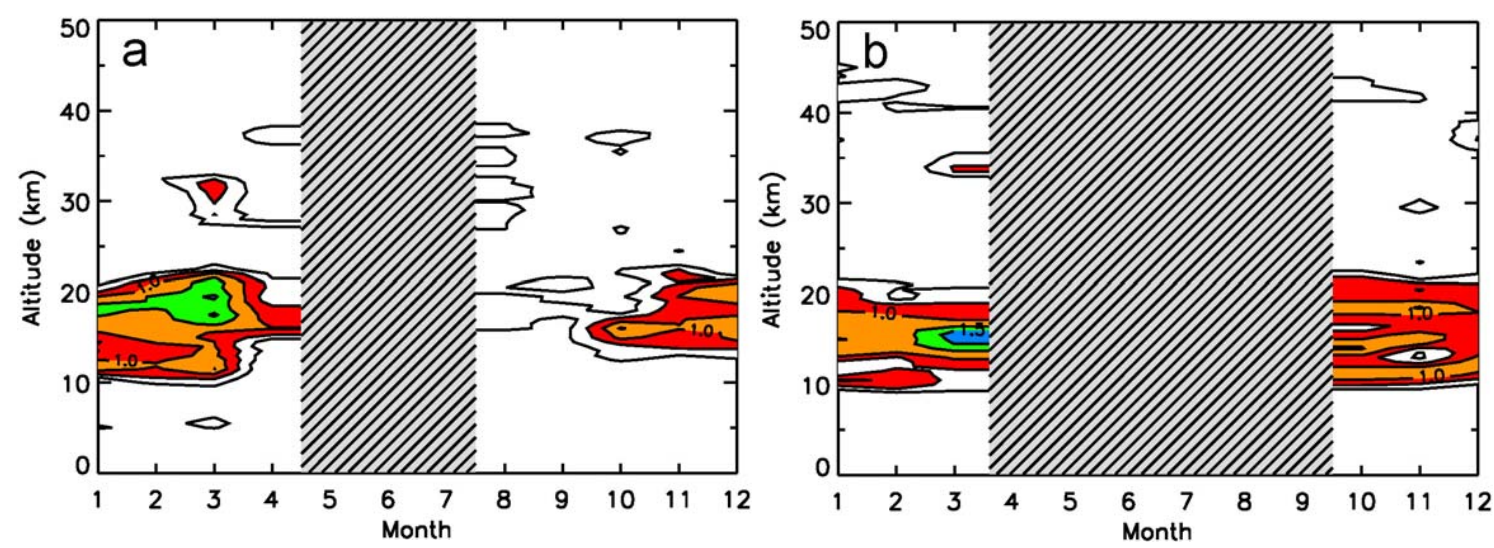

Fig. 4. Time-altitude contour plot of $\delta$ for the (a) tropical and midlatitude regimes and (b) midlatitude and polar regimes. The contours are drawn at 0.25 intervals starting with 0.50. $\delta$ has been calculated using Eq. (2) of Sparling (2000). The grey hatched areas indicate months for which there were not enough data points to calculate $\delta$.

2003). The apparent decrease in meteorological influence shown in Fig. 4a for April is surprising. August and September show little distinction between the tropical and midlatitude regime, even in the $10-20 \mathrm{~km}$ range. This lack of distinction is due to the minimum in the latitudinal gradient in the total ozone field in late summer and early fall. During this time of year, the difference in mean total ozone between regimes is at a minimum (30 DU) (Hudson et al., 2006), as is the difference in tropopause height. In addition, summer is known to be a time of maximum STE due to the summer monsoon circulation (Chen, 1995; Dunkerton, 1995; Pan et al., 1997). Further, Haynes and Shuckburgh (2000) showed effective diffusivity $\left(\kappa_{\text {eff }}\right)$ as a function of altitude and reported maximum values of $\kappa_{\text {eff }}$ in the summer and fall relative to the winter and spring poleward of $30^{\circ}$ equivalent latitude at all stratospheric levels up to $\sim 20 \mathrm{~km}$.
The winter and early spring are times of maximum difference between regimes in mean total ozone. The difference can be as high as 70DU in March. This is consistent with the relatively large values of $\delta$ in March in Fig. 4a, and in Fig. 4b. Haynes and Shuckburgh (2000) observed a mixing barrier associated with the subtropical front from $\sim 8-15 \mathrm{~km}$ $(330-390 \mathrm{~K})$, with the minimum in $\kappa_{\text {eff }}$ in winter. Various studies have reported a minimum in STE during this time of year (Chen, 1995; Pan et al., 2000; Berthet et al., 2007). The range of $\delta>0.75$ seen in Fig. 4 does extend slightly higher in altitude than the barrier to mixing seen in Haynes and Shuckburgh (2000).

The monthly mean ozonepause heights for the tropical (red), midlatitude (green) and polar (blue) regimes are shown in Fig. 5. These monthly means are calculated by first finding the ozonepause altitudes of the individual profiles, and are therefore slightly different from the ozonepause of the 
average profile. The results are nevertheless consistent with the profiles shown in Figs. 2 and 3; the highest ozonepause heights are seen in the tropical regime, and the lowest in the polar. Similar to Fig. 3, the one-sigma standard deviation of the means are shown as dashed lines on either side of the means. The overlapping distributions seen in Fig. 5 reflect the large latitude band chosen for analysis. As discussed in Hudson et al. (2006), while the regimes do classify total ozone columns into distinct groups, there remains a small latitude dependence in total ozone within each regime. This latitude dependence in the ozone column is influenced by the latitude dependence in tropopause height; tropopause height generally decreases with increasing latitude. For example, high-latitude tropical profiles will generally have lower ozonepause heights than low-latitude tropical profiles. The climatological zonal average ozonepause for $25^{\circ}-60^{\circ} \mathrm{N}$ is also shown in Fig. 5 as a black line to illustrate the large deviations from the zonal mean seen when utilizing the method of meteorological regimes.

Figure $6 \mathrm{a}-\mathrm{d}$ shows the column amounts for each regime for the altitude intervals $10-20 \mathrm{~km}, 20-30 \mathrm{~km}, 30-40 \mathrm{~km}$, and $40-50 \mathrm{~km}$, respectively. It should be noted that the ozone column amount shown in Fig. 6a is only the stratospheric component. The seasonal cycles of each regime in the lower stratosphere, seen in Fig. 6a, show recognizable features of the distribution of total ozone, e.g. the increase in amplitude with latitude, and the spring maximum (Appenzeller et al., 1996). These features also agree with the results observed by Logan (1999) who showed the seasonal variation in the ozone column from the tropopause to $100 \mathrm{hPa}$ for several ozonesonde stations. Figure $6 \mathrm{~b}$ shows the results for the 20-30 km region. Based on Figs. 3 and 4, a significant difference between regimes is not expected in this altitude region. These altitudes are a transition region between the synoptically dominated lower stratosphere and the more zonally symmetric mid- to upper stratosphere (Solomon and Brasseur, 1984; Rosenlof et al., 1997; Logan, 1999; Staehelin et al., 2001). Figure $6 \mathrm{c}$ and $\mathrm{d}$ is in the upper stratosphere and as such, shows summer maximums in column amount (Logan, 1999). As expected, no distinction between regimes is seen in Fig. $6 \mathrm{c}$ and d.

Figure $7 \mathrm{a}$ and $\mathrm{b}$ shows the HALOE climatologies seen in Fig. 3 (solid lines) in addition to climatologies calculated using data from SAGE (dash dot dash lines). The one sigma standard deviations for the SAGE climatologies were on the order or smaller than those for HALOE, so they were not included on the figure. As anticipated, similar to the HALOE climatologies, distinct ozonepause heights are seen. The climatologies agree up to $\sim 22 \mathrm{~km}$ in both March and September. At higher altitudes, where ozone becomes increasingly correlated with latitude and less with lower stratospheric dynamics, differences between the mean profiles from SAGE and HALOE result from differences in their sampling patterns. This emphasizes the decrease in atmospheric variability below $22 \mathrm{~km}$ when within a meteorological regime.

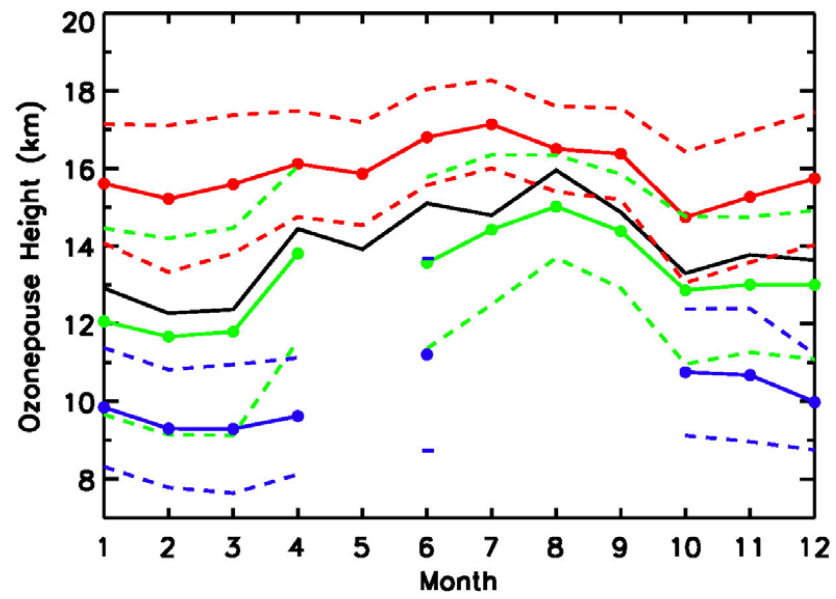

Fig. 5. Ozonepause height climatologies calculated from 19972004 between $25^{\circ}$ and $60^{\circ} \mathrm{N}$ for the tropical (red), midlatitude (green), and polar (blue) regimes. These monthly means are calculated by first finding the ozonepause altitudes of the individual profiles, and are therefore slightly different from the ozonepause of the average profile. The black line is the zonally averaged ozonepause height. The one-sigma standard deviations of the means are shown as dashed lines and are shown in the same color scheme as the means.

\section{Water vapor profile classification}

Both ozone and water vapor mixing ratios increase with altitude in the lower and mid stratosphere, but whereas ozone mixing ratios in the troposphere are smaller than in the stratosphere, the troposphere is much wetter than the stratosphere. Hence, in segregating water vapor profiles by meteorological regime we expect to find variations which differ from those observed in ozone. Because of the very large water vapor mixing ratios in the troposphere relative to the stratosphere, the seasonal variations in water vapor mixing ratios in the LMS are particularly sensitive to stratosphere-troposphere exchange (Rosenlof et al., 1997; Pan et al., 2000; Berthet et al., 2007). Dessler and Sherwood (2004) estimate that convection increases extratropical water vapor at $380 \mathrm{~K}$ by $40 \%$, while decreasing ozone by only a few percent.

Water vapor in this region of the atmosphere has a long chemical lifetime, and is considered to be an excellent tracer of motion and transport (Brewer, 1948; Mote et al., 1996; Chiou et al., 2006). In the LMS, water vapor will be a combination of high mixing ratio air that has subsided from the upper stratosphere, low mixing ratio air that has traveled across the cold tropical tropopause, and very high mixing ratio air that has crossed from the troposphere to the stratosphere outside the tropics (Rosenlof et al., 1997; Pan et al., 2000; Randel et al., 2001; Berthet et al., 2007). The extent to which an air parcel is influenced by these sources of water vapor will vary by meteorological regime. Because the $\delta$-test of chemical distinctness cannot distinguish higher water vapor 

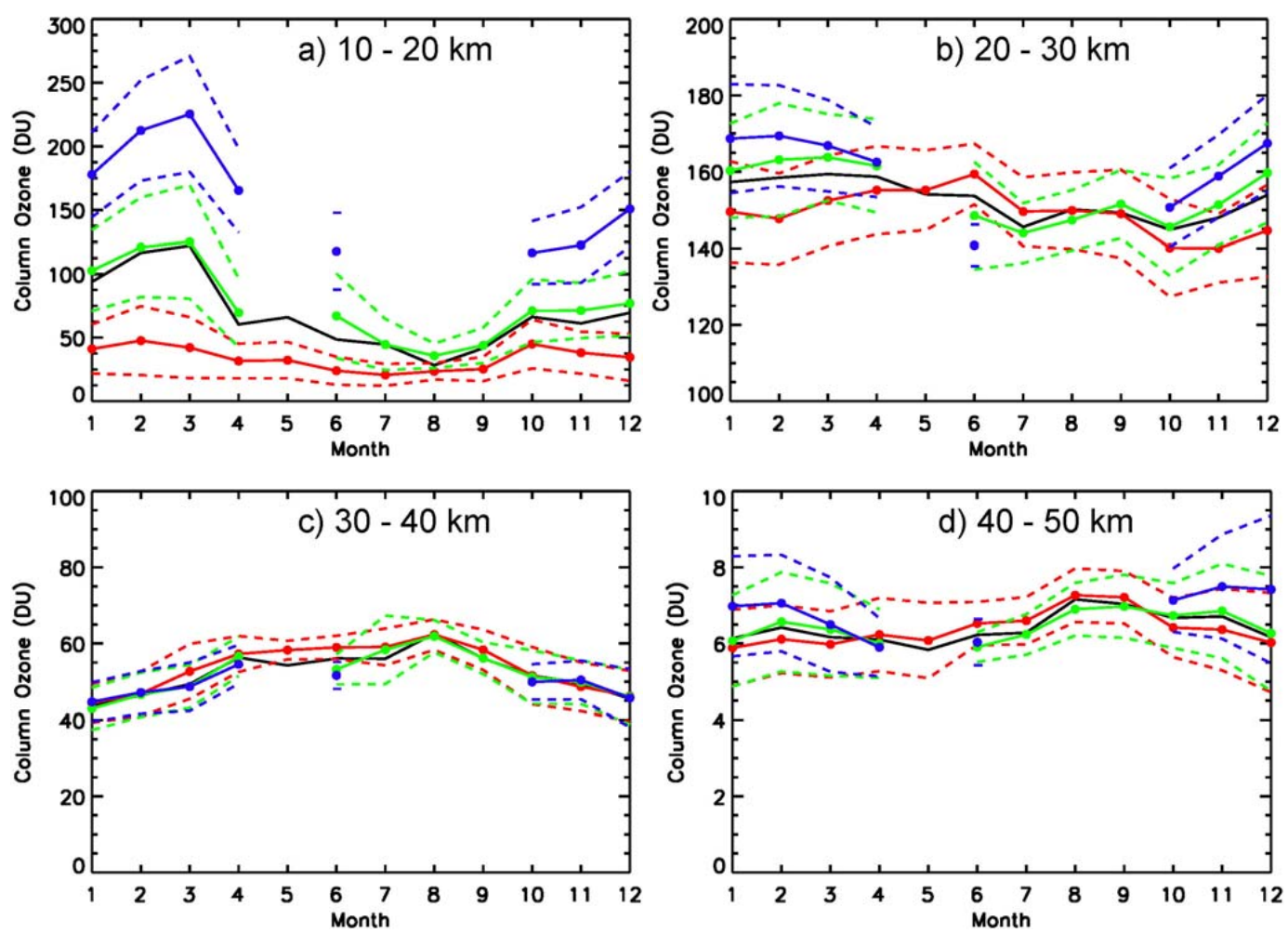

Fig. 6. Stratospheric column ozone climatologies (in DU) calculated from 1997-2004 between $25^{\circ}$ and $60^{\circ} \mathrm{N}$ for (a) $10-20 \mathrm{~km}$, (b) $20-$ $30 \mathrm{~km}$, (c) $30-40 \mathrm{~km}$, and (d) $40-50 \mathrm{~km}$. Note the different scales. The solid lines with filled circles indicate the tropical (red), midlatitude (green), and polar (blue) regimes. The black line is the zonally averaged stratospheric column ozone. The one-sigma standard deviations of the means are shown as dashed lines and are shown in the same color scheme as the means.
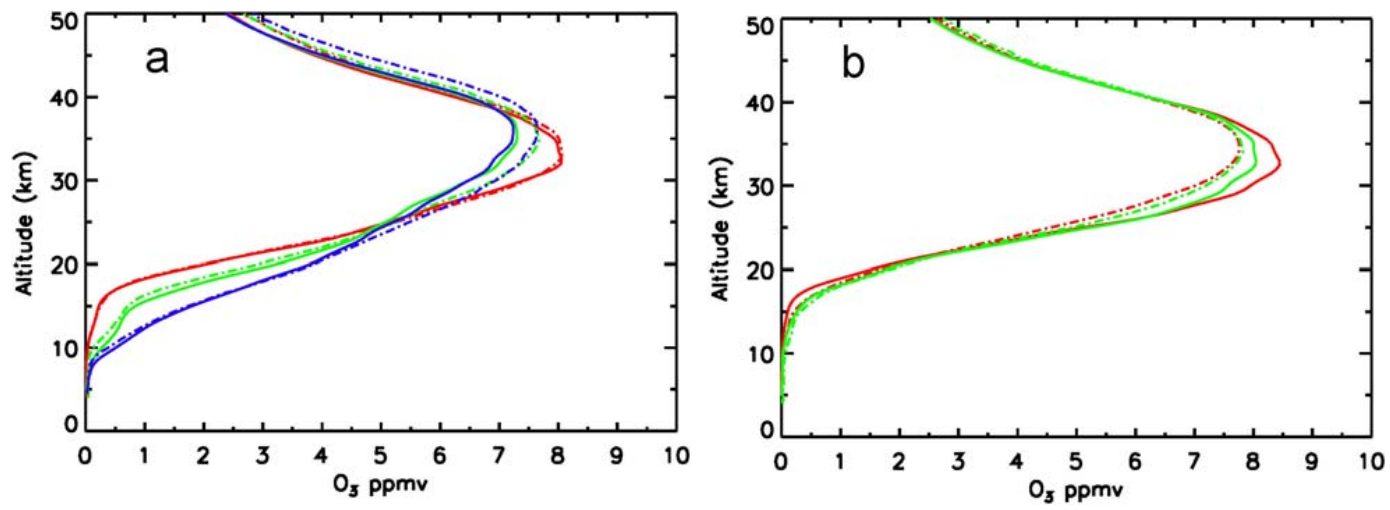

Fig. 7. HALOE (solid lines) and SAGE (dash dot dash lines) ozone profile climatologies calculated from $1997-2004$ between $25^{\circ}$ and $60^{\circ} \mathrm{N}$ for (a) March and (b) September. The color scheme is: red - tropical, green - midlatitude, and blue - polar.

mixing ratios resulting from descent of oxidized air from wet air crossing the tropopause into the stratosphere, we have not applied this test to the water vapor profiles.

\subsection{One day}

The total ozone field, boundaries, and location of each HALOE sunset measurement taken on 18 February 1998 can be seen in Fig. 1. Similar to Fig. 2, Fig. 8a-c shows the individual profiles that have been classified into the polar, midlatitude, and tropical regimes, respectively. All of the profiles show a minimum below $20 \mathrm{~km}$, and then increasing mixing ratios with increasing altitude, corresponding to the formation of water vapor through the oxidation of methane (Letexier et al., 1988). The variability of the altitude of the 

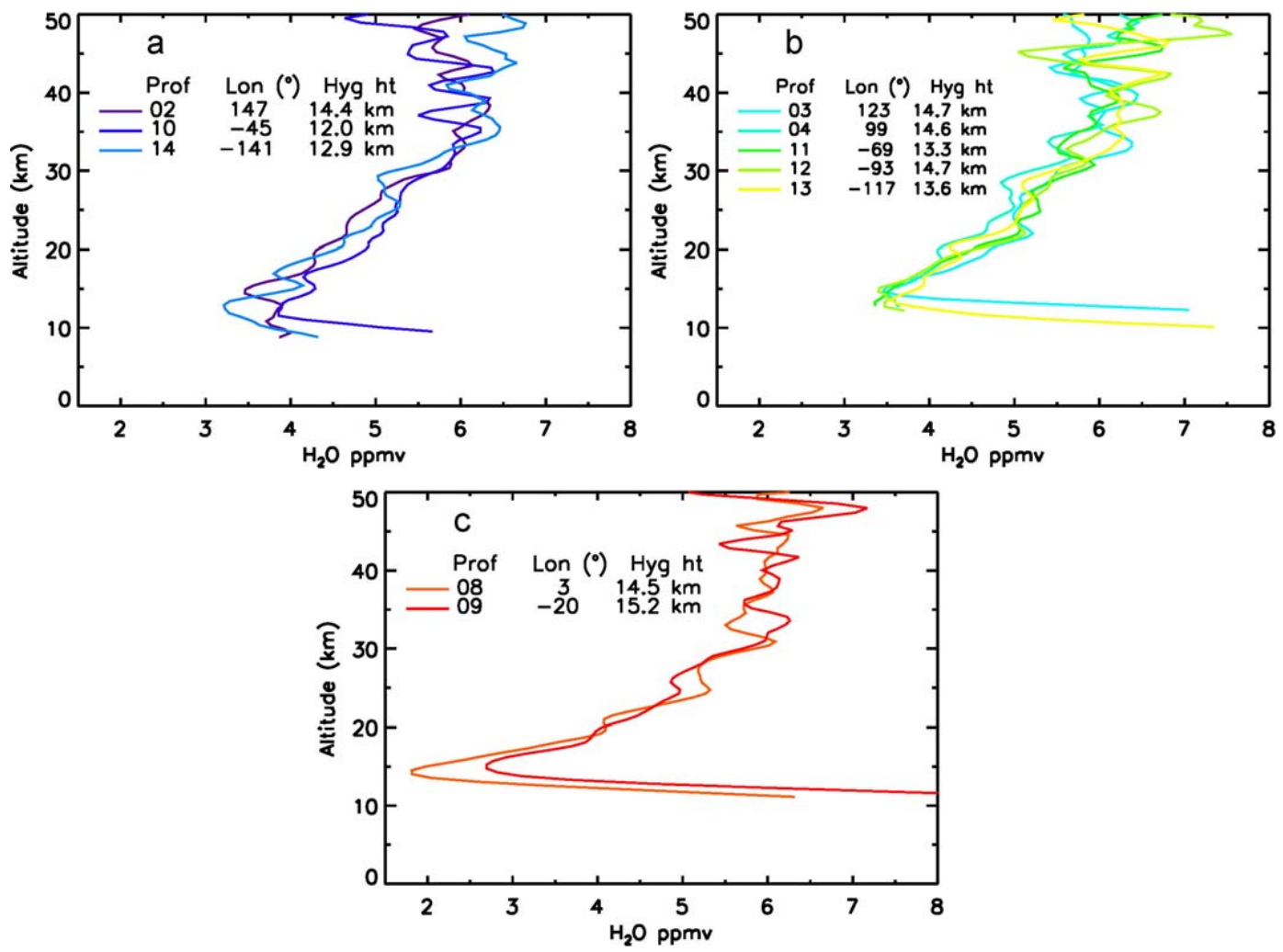

Fig. 8. HALOE water vapor profiles that correspond to the colored symbols on Fig. 1 for 18 February 1998 for the (a) polar regime, (b) midlatitude regime, and c) tropical regime. The profile numbers, longitudes, and hygropause heights are also listed.

hygropause, which we take here to be simply the altitude of the lowest water vapor mixing ratio, is much larger than the variability seen around the ozonepause region in Fig. 2. Profiles 10 and 14, seen in Fig. 8a, have similar hygropause heights, around $12-13 \mathrm{~km}$. Profile 2 has a hygropause height at $\sim 14.5 \mathrm{~km}$; however another local minimum exists below, at around $11 \mathrm{~km}$. Also worth noting is the increased variability in the value of the minimum. In Fig. 8a, the hygropause values range from $\sim 3-4 \mathrm{ppmv}$. Figure $8 \mathrm{~b}$ shows the five profiles classified as midlatitude. These profiles have hygropause heights ranging from $13-15 \mathrm{~km}$. The two tropical profiles are shown in Fig. 8c, and have hygropause heights at 14.5 and $15.2 \mathrm{~km}$.

Water vapor profiles show differences between meteorological regimes, but unlike ozone where the difference is well described by differences in ozonepause altitude, the distinction in water vapor is sometimes more clearly seen not by the altitude but by the mixing ratio at the hygropause. Thus, the low water vapor mixing ratios in the two tropical profiles in Fig. 8c suggest that most of this air has recently passed through the tropical tropopause and has therefore not experienced significant methane oxidation. These low water vapor values, and examinations of the profiles in Fig. 2c, support the interpretation that the tongue of low ozone seen in Fig. 1 is tropical in nature and not the result of mixing in of ozone depleted air from the arctic vortex.

\subsection{Climatology}

Monthly water vapor climatologies were calculated using data from both SAGE and HALOE for the period 1997-2004 between $25^{\circ}$ and $60^{\circ} \mathrm{N}$. Figure 9a-d shows the March, June, September, and December monthly water vapor climatologies, respectively, calculated using data from HALOE. The one-sigma standard deviations are shown as dashed lines, and the numbers of profiles used to calculate the climatologies are shown in the right-hand subpanels. The subtropical, midlatitude, and polar regimes are shown as red, green, and blue lines, respectively.

The March, June, and December climatologies show that the types of differences between meteorological regimes observed in the 18 February 1998 profiles are observed over several months. While the December climatology does not show any clear distinction between the midlatitude and polar profiles, the March and June climatologies shows a hygropause which does, just as in the case of the ozonepause for those months, decrease in altitude from the tropical to midlatitude regime and from the midlatitude to the polar regime. In March, distinction between regimes is reflected in the water vapor mixing ratio at the hygropause as well as the altitudes. This is true for December through April. From May to November, the hygropause values for each regime are similar, as seen in Fig. 9b and c. Just as for ozone, water 

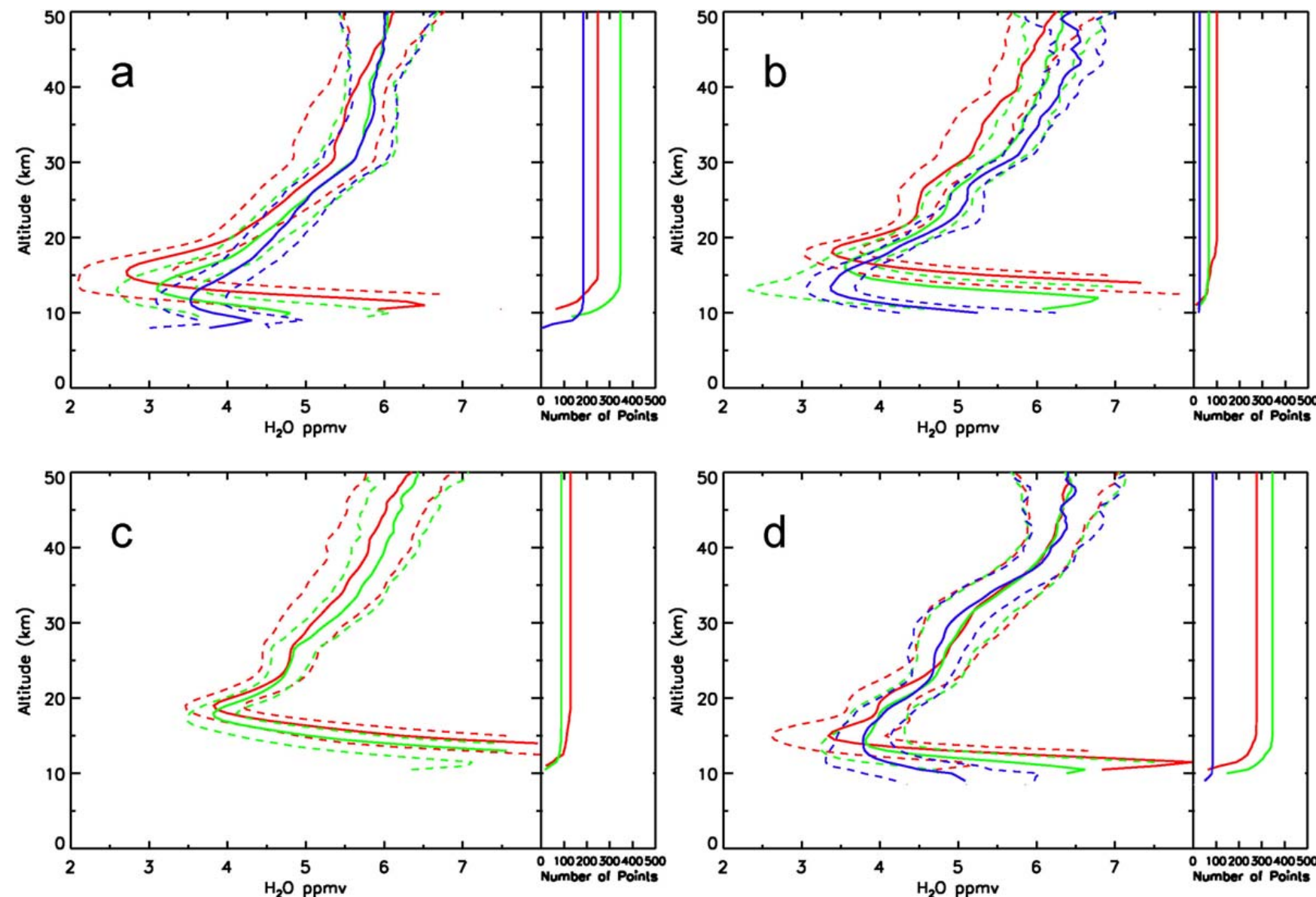

Fig. 9. HALOE water vapor profile climatologies calculated from 1997-2004 between $25^{\circ}$ and $60^{\circ} \mathrm{N}$ for (a) March, (b) June, (c) September, and (d) December. The one-sigma standard deviations are shown as dashed lines, and the number of points are shown on the right. The color scheme is: red - tropical, green - midlatitude, and blue - polar.

vapor profiles in September show little distinction between regimes.

The seasonal cycle of the hygropause altitudes of each regime: tropical (red), midlatitude (green) and polar (blue), can be seen in Fig. 10. The one-sigma standard deviations of the means are shown as dashed lines, and the zonal mean between $25^{\circ}$ and $60^{\circ} \mathrm{N}$ is shown as a black solid line. All three regimes show similar seasonal cycles, all having a summer maximum and winter minimum.

It is interesting to compare the regime dependence in the hygropause heights relative to that of the ozonepause heights. The difference in the hygropause height of the tropical and midlatitude regimes (and of the midlatitude and polar regimes) generally differs by $\sim 1 \mathrm{~km}$, while the ozonepause heights for these regimes differ by $\sim 2-4 \mathrm{~km}$. The smaller difference in hygropause heights between regimes may be due to water vapor entering the lowermost stratosphere in the midlatitude and polar regimes isentropically without crossing the cold tropical tropopause, and subsequently raising the hygropause height above the tropopause height. Such transport is especially prevalent in the summer (Chen, 1995; Dessler and Sherwood, 2004).

Figure $11 \mathrm{a}$ and $\mathrm{b}$ shows mean water vapor mixing ratios at $15 \mathrm{~km}$ and $18 \mathrm{~km}$, respectively, for each regime. At $15 \mathrm{~km}$, the tropical regime (red line) shows increasing values from March to July, and decreasing values from August to February. The very low water vapor mixing ratios in the tropical regime from December through March occur during the period of minimum tropical cold-point temperatures (Seidel et al., 2001). As is shown in Fig. 10, $15 \mathrm{~km}$ is near the height of the tropical regime hygropause, so this air represents the minimum in the tape recorder signal (Mote et al., 1996) that is slowly transported to higher altitudes in the following months. From June through September, the water vapor mixing ratios observed indicate that this altitude lies in the upper troposphere.

At $18 \mathrm{~km}$ (Fig. 11b), the tropical regime exhibits decreasing mixing ratios from December to May, increasing water vapor mixing ratios from May through July, and then relatively constant values from July through December. This 
minimum water vapor in May is a result of the rising tape recorder minimum which was near $15 \mathrm{~km}$ in February. The seasonal cycles of the tropical regime observed at both altitude levels agree well with Randel et al. (2001), who examined water vapor vs. equivalent latitude on the $390 \mathrm{~K}$ potential temperature surface and observed fast meridional transport at this level bringing dry air poleward. Although the minimum mean tropical regime hygropause mixing ratio is in February (not shown), the influence of decreasing tropical tropopause temperatures, subsequent dehydration, and quasihorizontal transport poleward is first seen in December. The climatological profile (shown in Fig. 9d) shows a sharp hygropause at $\sim 15 \mathrm{~km}$ (Fig. 9d); significantly lower than the mean hygropause above $18 \mathrm{~km}$ seen in November.

In the midlatitude regime at 15 and $18 \mathrm{~km}$ (Fig. 11, green line), decreasing mixing ratios are seen from January to April. In the LMS, both water vapor and ozone generally increase with altitude. Therefore, increased descent in the winter brings down air with higher mixing ratios, as is observed in the corresponding ozone mixing ratios (not shown). However, in the midlatitude regime, the water vapor values seen at these altitudes do not show an increase during this period, demonstrating the influence of air from the tropics that has recently passed through the tropical cold point tropopause. The large increase in midlatitude water vapor seen at $15 \mathrm{~km}$ from June to August occurs above the mean ozonepause, but is not seen at $18 \mathrm{~km}$. This increase is most likely due to both the occasional sampling of upper tropospheric water vapor and isentropic cross tropopause transport which avoids the tropical cold point tropopause (Chen, 1995; Dessler and Sherwood, 2004).

The seasonal cycle of the polar regime is difficult to determine due to the number of missing months, but the increasing mixing ratios at $18 \mathrm{~km}$ (Fig. 11b, blue line) from December to April is coincident with an increase in polar regime ozone at this altitude, and is probably caused by the descent of stratospheric air with higher water vapor mixing ratios, as discussed above.

In Fig. 12 we show the climatological HALOE water vapor profiles, along with climatologies calculated using data from SAGE. On these figures, the solid lines represent the HALOE data, the dash-dot-dash lines represent the SAGE data, and the color scheme is the same as the previous figure. Overall, the SAGE climatologies show good agreement with those of HALOE in the LMS, although with respect to hygropause altitude, HALOE is biased low in the winter months. In March, both instruments show similar changes in hygropause altitude from the subtropical through the polar regime, and similar changes in the hygropause mixing ratio. In June both instruments show that the primary distinguishing feature between the regimes is the hygropause altitude, and not the mixing ratio. Just as for ozone, both instruments show that the subtropical and midlatitude regimes have very similar profiles in the LMS in September. In December, both instruments show a narrow hygropause in the subtropics, but

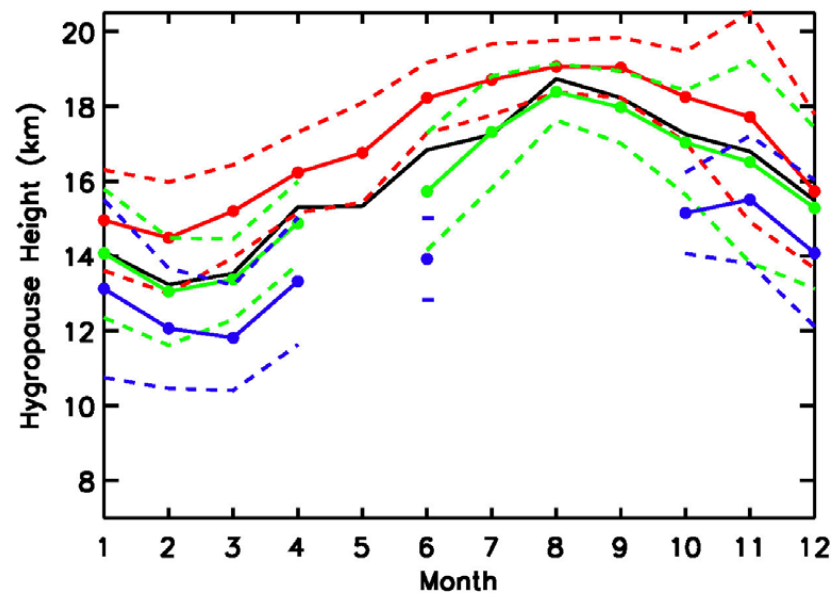

Fig. 10. Hygropause height climatologies calculated from 19972004 between $25^{\circ}$ and $60^{\circ} \mathrm{N}$ for the tropical (red), midlatitude (green), and polar (blue) regimes. The black line is the zonally averaged hygropause height. The one-sigma standard deviations of the means are shown as dashed lines and are shown in the same color scheme as the means.

a broad hygropause region in both the midlatitude and polar regimes.

\section{Conclusions}

Several methods exist to account for dynamical variability. Here, we have used daily measurements of total ozone to locate the upper troposphere fronts, and have shown using data from HALOE and SAGE that, below $\sim 20 \mathrm{~km}$, the meteorological regimes between these fronts are characterized by unique ozone and water vapor profile shapes. This distinction was found to be greatest in the winter and spring and weakest in the summer and fall.

The ozone profiles analyzed showed distinct ozonepause heights within each regime over both daily and climatological timescales, with the tropical regime exhibiting the highest ozonepause heights, and the polar the lowest. A measure of distinctness, $\delta$, was calculated using Eq. (2) from Sparling (2000). Values of $\delta>0.75$ were observed from $\sim 10-20 \mathrm{~km}$ in the months of November through March. This agrees well with previous observations of the extent, in altitude, of meteorological influence (Logan, 1999; Koch et al., 2002; Newchurch et al., 2003). In August and September, little to no distinction is seen due to a minimum in the latitudinal gradient in total ozone (Hudson et al., 2006), in part due to a maximum in STE (Chen, 1995; Dunkerton, 1995; Pan et al., 1997; Haynes and Shuckburgh, 2000) during this time of year. The influence of regimes was also emphasized by the excellent agreement between the HALOE and SAGE climatologies below $\sim 22 \mathrm{~km}$, despite differences in the latitude sampling of the measurements, chosen wavelengths, and retrieval techniques. 

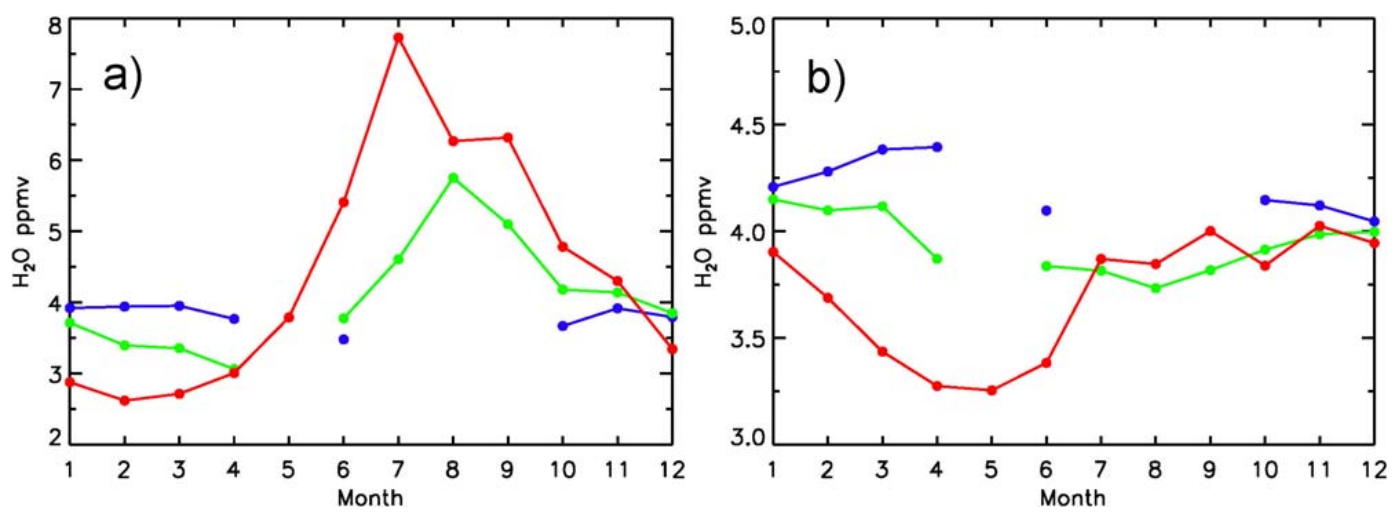

Fig. 11. Climatological HALOE water vapor mixing ratios at (a) $15 \mathrm{~km}$ and (b) $18 \mathrm{~km}$ for the tropical (red), midlatitude (green), and polar (blue) regimes.
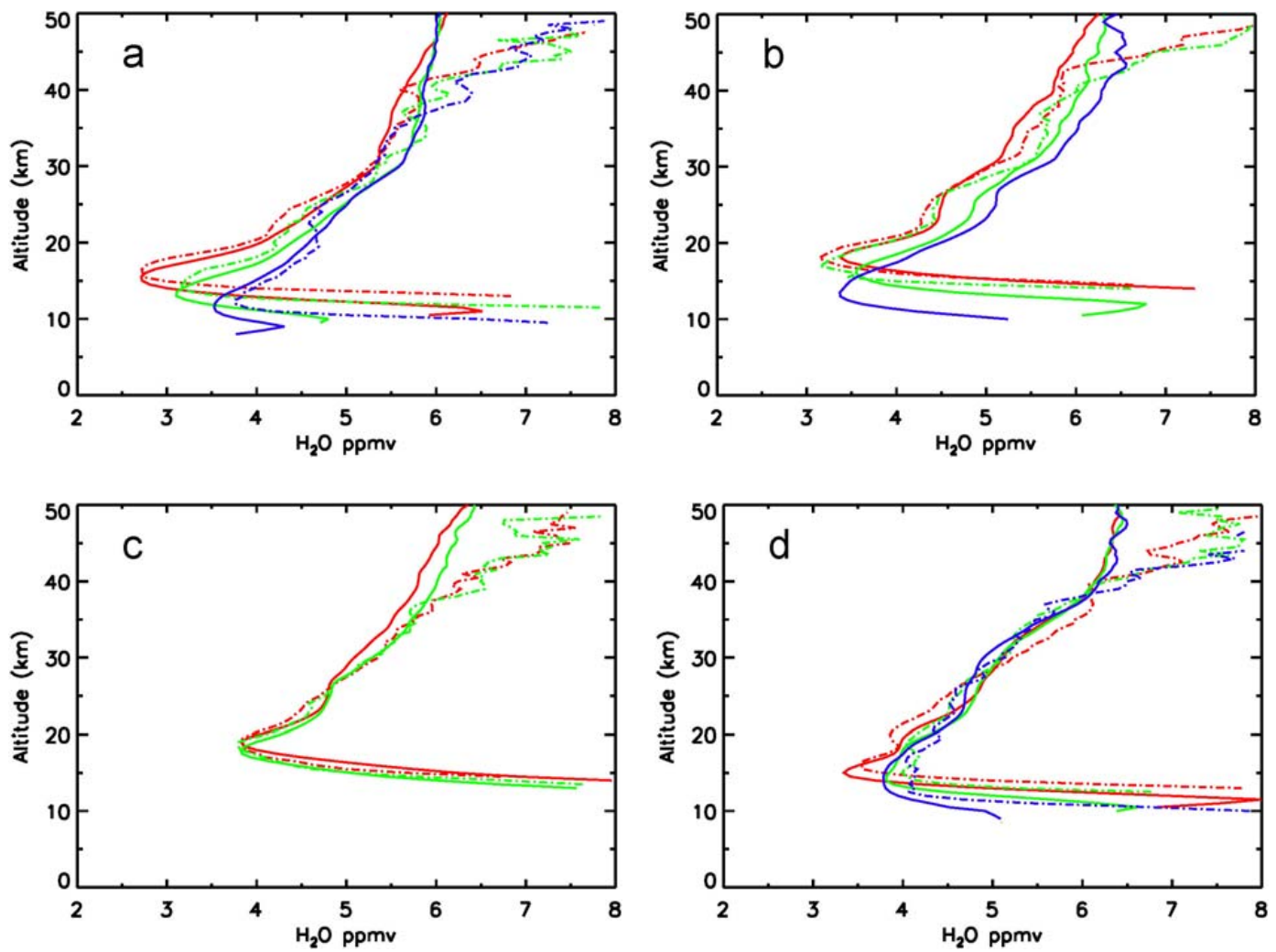

Fig. 12. HALOE and SAGE water vapor profile climatologies calculated from 1997-2004 between $25^{\circ}$ and $60^{\circ} \mathrm{N}$ for (a) March, (b) June, (c) September, and (d) December. HALOE data is shown as solid lines, and SAGE data is shown as dash-dot-dash lines. The color scheme is: red - tropical, green - midlatitude, and blue - polar.

The relationship between meteorological influence and altitude was further examined using stratospheric column ozone amounts at various altitude intervals. From 10-20 km, each regime was characterized by distinctly different column amounts and displayed seasonal cycles with March maxima. At higher altitudes the distinction between regimes diminished, and the seasonal cycles exhibited summer maxima.
For water vapor, the distinction between regimes was most easily seen in differences in hygropause height and, in some months (December through April), hygropause mixing ratios. March showed the clearest distinction between regimes, displaying distinct hygropause heights and hygropause mixing ratios for each regime. Similar to the ozone climatologies, September showed the least differentiation. When the HALOE water vapor climatologies were compared with 
those using SAGE data, good agreement was obtained, although HALOE exhibited low hygropause heights with respect to SAGE in the winter months. As with ozone, the SAGE water vapor climatologies showed consistent results with those of HALOE with respect to distinction between meteorological regimes.

The seasonal cycle of water vapor in the tropical regime was examined at particular altitudes $(15 \mathrm{~km}$ and $18 \mathrm{~km})$. Since the tropical regime lies equatorward of the subtropical front, there are no isentropic STE pathways to the LMS. Therefore, air in the LMS of the tropical regime will be a mixture of air that has crossed the tropical tropopause and air that has descended from the middle stratosphere. Our results indicate that air that has crossed the tropical tropopause and been quasi-horizontally transported poleward controls the annual cycle of water vapor in the LMS of the tropical regime, agreeing with previous work (Rosenlof et al., 1997).

The influence of the annual cycle in tropical cold point temperatures is also evident in the midlatitude regime at both altitude levels. This was clearly seen in winter at $15 \mathrm{~km}$ when water vapor ratios decreased, rather than increased due to subsidence from the Brewer Dobson circulation. As with ozone, the effects of isentropic STE are seen in the seasonal cycle of the midlatitude regime at $15 \mathrm{~km}$ in the summer and fall.

This study uses HALOE measurements to provide a monthly climatological profile for ozone and water vapor for each of the meteorological regimes. As Hudson et al. (2003, 2006) showed, changes in the relative weighting of these regimes over time could contribute to trends in total ozone in a particular zonal band. This study can be used to improve our understanding of how changes in these regimes will affect trends in the UTLS.

Acknowledgements. The early part of this work was funded by a grant from the NASA Science Mission Directorate and later by the Naval Research Laboratory. This work was also performed in part while M. Follette-Cook held a National Research Council Research Associateship award at the Naval Research Laboratory. The SAGE II data were processed and provided by the NASA Langley Research Center (NASA-LaRC) and the NASA Langley Radiation and Aerosols Branch; the HALOE data were obtained from the HALOE website: http://haloe.gats-inc.com/home/index.php; and the TOMS data were obtained from the TOMS website: http://toms.gsfc.nasa.gov/. The authors would like to thank the reviewers for their helpful and insightful feedback.

Edited by: P. Haynes

\section{References}

Allen, D. R. and Nakamura, N.: Tracer equivalent latitude, A diagnostic tool for isentropic transport studies, J. Atmos. Sci., 60, 287-304, 2003.
Appenzeller, C., Holton, J. R., and Roselof, K. H.: Seasonal variation in mass transport across the tropopause, J. Geophys. Res., 101(D10), 15071-15078, 1996.

Archer, C. L. and Caldeira, K.: Historical trends in the jet streams, Geophys. Res. Lett., 35, L08803, doi:10.1029/2008GL033614, 2008.

Berthet, G., Esler, J. G., and Haynes, P. H.: A lagrangian perspective of the tropopause and the ventilation of the lower stratosphere, J. Geophys. Res., 112, D18102, doi:10.1029/2006JD008295, 2007.

Bethan, S., Vaughan, G., and Reid, S. J.: A comparison of ozone and thermal tropopause heights and the impact of tropopause definition on quantifying the ozone content of the atmosphere, Q. J. Roy. Meteorol. Soc., 122, 929-944, 1996.

Bhatt, P. P., Remsberg, E. E., Gordley, L. L., McInerney, J. M., Brackett, V. G., and Russell III, J. M.: An evaluation of the quality of Halogen Occultation Experiment ozone profiles in the lower stratosphere, J. Geophys. Res., 104(D8), 9261-9275, 1999.

Bluestein, H. B.: Synoptic-dynamic meteorology in midlatitudes: Vol II, Oxford University Press, New York, NY, 594 pp, 1993.

Brasseur, G. and Solomon, S.: Aeronomy of the middle atmosphere, D. Reidel Publishing Company, Dordrecht, Holland, 441 pp, 1984

Brewer, A. W.: Evidence for a world circulation provided by the measurements of helium and water vapour distribution in the stratosphere, Q. J. Roy. Meteorol. Soc., 75, 351-363, 1949.

Brühl, C., Drayson, S. R., Russell III, J. M., et al.: Halogen Occultation Experiment ozone channel validation, J. Geophys. Res., 101(D6), 10217-10240, 1996.

Butchart, N. and Remsberg, E. E.: The area of the stratospheric polar vortex as a diagnostic for tracer transport on an isentropic surface, J. Atmos. Sci., 43, 1319-1339, 1986.

Chen, P.: Isentropic cross-tropopause mass exchange in the extratropics, J. Geophys. Res., 100(D8), 16661-16673, 1995.

Chiou, E. W., Thomason, L. W., and Chu, W. P.: Variability of stratospheric water vapor inferred from SAGE II, HALOE, and Boulder (Colorado) balloon measurements, J. Climate, 19, 41214133, 2006.

Chu, W. P., McCormick, M. P., Lenoble, J., Brogniez, C., and Pruvost, P.: SAGE II inversion algorithm, J. Geophys. Res., 94(D6), 8339-8351, 1989.

Cunnold, D. M., Chu, W. P., Barnes, R. A., McCormick, M. P., and Veiga, R. E.: Validation of SAGE II ozone measurements, J. Geophys. Res., 94, 8447-8460, 1989.

Danielsen, E. F.: Stratospheric-tropospheric exchange based on radioactivity, ozone and potential vorticity, J. Atmos. Sci., 25, 502$518,1968$.

Defant, F. and Taba, H.: The threefold structure of the atmosphere and the characteristics of the tropopause, Tellus, 9, 259-274, 1957.

Dessler, A. E., Hintsa, E. J., Weinstock, E. M., Anderson, J. G., and Chan, K. R.: Mechanisms controlling water vapor in the lower stratosphere: "A tale of two stratosphere", J. Geophys. Res., 100(D11), 23167-23172, 1995.

Dessler, A. E. and Sherwood, S. C.: Effect of convection on the summertime extratropical lower stratosphere, J. Geophys. Res., 109, D23301, doi:10.1029/2004JD005209, 2004.

Dobson, G. M., Harrison, D. N., and Lawrence, J.: Measurements 
of the amount of ozone in the Earth's atmosphere and its relation to other geophysical conditions - Part III, Proc. Roy. Soc. Lond., A122, 456-486, 1929.

Dunkerton, T. J.: Evidence of meridional motion in the summer lower stratosphere adjacent to monsoon regions, J. Geophys. Res., 100, 16675-16688, 1995.

Fischer, H., Wienhold, F. G., Hoor, P., Bujok, O., Schiller, C., Siegmund, P., Ambaum, M., Scheeren, H. A., and Lelieveld, J.: Tracer correlations in the northern high latitude lowermost stratosphere: Influence of cross-tropopause mass exchange, Geophys. Res. Lett., 27(1), 97-100, 2000.

Fu, Q., Johanson, C. M., Wallace, J. M., and Reichler, T.: Enhanced mid-latitude tropospheric warming in satellite measurements, Science, 312, 1179, 2006.

Grooß, J.-U. and Russell III, J. M.: Technical note: A stratospheric climatology for $\mathrm{O}_{3}, \mathrm{H}_{2} \mathrm{O}, \mathrm{CH}_{4}, \mathrm{NO}_{\mathrm{x}}, \mathrm{HCl}$ and $\mathrm{HF}$ derived from HALOE measurements, Atmos. Chem. Phys., 5, 2797-2807, 2005, http://www.atmos-chem-phys.net/5/2797/2005/.

Haynes, P. and Shuckburgh, E.: Effective diffusivity as a diagnostic of atmospheric transport. 2. Troposphere and lower stratosphere, J. Geophys. Res., 105(D18), 22795-22810, 2000.

Hegglin, M. I., Brunner, D., Peter, T., Hoor, P., Fischer, H., Staehelin, J., Krebsbach, M., Schiller, C., Parchatka, U., and Weers, U.: Measurements of $\mathrm{NO}, \mathrm{NO}_{\mathrm{y}}, \mathrm{N}_{2} \mathrm{O}$, and $\mathrm{O}_{3}$ during SPURT: implications for transport and chemistry in the lowermost stratosphere, Atmos. Chem. Phys., 6, 1331-1350, 2006, http://www.atmos-chem-phys.net/6/1331/2006/.

Hervig, M. and McHugh, M.: Cirrus detection using HALOE measurements, Geophys. Res. Lett., 26, 719-722, 1999.

Hitchman, M. H., McKay, M., and Trepte, C. R.: A climatology of stratospheric aerosol, J. Geophys. Res., 99, 20689-20700, 1994.

Hoinka, K. P., Claude, H., and Köhler, U.: On the correlation between tropopause pressure and ozone above central Europe, Geophys. Res. Lett., 23, 1753-1756, 1996.

Holton, J. R., Haynes, P. H., McIntyre, M. E., Douglass, A. R., Rood, R. B., and Pfister, L.: Stratosphere-troposphere exchange, Rev. Geophys., 33, 403-440, 1995.

Hoor, P., Fischer, H., Lange, L., Lelieveld, J., and Brunner, D.: Seasonal variations of a mixing layer in the lowermost stratosphere as identified by the $\mathrm{CO}-\mathrm{O}_{3}$ correlation from in situ measurements, J. Geophys. Res., 107, 4044, doi:10.1029/2000JD000289, 2002.

Hoskins, B. J., McIntyre, M. E., and Robertson, A. W.: On the use and significance of isentropic potential vorticity maps, Q. J. Roy. Meteorol. Soc., 111, 877-946, 1985.

Hoskins, B. J.: Towards a PV-theta view of the general circulation, Tellus, 43AB, 27-35, 1991.

$\mathrm{Hu}, \mathrm{Y}$. and Fu, Q.: Observed poleward expansion of the Hadley circulation since 1979, Atmos. Chem. Phys., 7, 5229-5236, 2007, http://www.atmos-chem-phys.net/7/5229/2007/.

Hudson, R. D., Frolov, A. D., Andrade, M. F., and Follette, M. B.: The total ozone field separated into meteorological regimes. Part I: Defining the regimes, J. Atmos. Sci., 60, 1669-1677, 2003.

Hudson, R. D., Andrade, M. F., Follette, M. B., and Frolov, A. D.: The total ozone field separated into meteorological regimes - Part II: Northern Hemisphere mid-latitude total ozone trends, Atmos. Chem. Phys., 6, 5183-5191, 2006, http://www.atmos-chem-phys.net/6/5183/2006/.

Karol, I. L., Klyagina, L. P., Frolov, A. D., and Shalamyansky, A.
M.: Fields of ozone and temperature within the boundaries of air masses, Meteor. Gidrol., 10, 47-52, 1987.

Kley, D., Stone, E. J., Henderson, W. R., Drummond, J. W., Harrop, W. J., Schmeltekopf, A. L., Thompson, T. L., and Winkler, R. H.: In situ measurements of the mixing ratio of water vapor in the stratosphere, J. Atmos. Sci., 36, 2513-2524, 1979.

Kley, D., Russell III, J. M., Phillips, C., et al.: SPARC assessment of upper tropospheric and stratospheric water vapor, WCRP 113, WMO/TD-1043, SPARC Rep. 2, World Clim. Res. Program, Geneva, 312 pp, 2000.

Koch, G., Wernli, H., Staehelin, J., and Peter, T.: A lagrangian analysis of stratospheric ozone variability and long-term trends above Payerne (Switzerland) during 1970-2001, J. Geophys. Res., 107, 4373, doi:10.1029/2001JD001550, 2002.

Letexier, H., Solomon, S., and Garcia, R. R.: The role of molecular hydrogen and methane oxidation in the water vapor budget of the stratosphere, Q. J. Roy. Meteorol. Soc., 114, 281-295, 1988.

Logan, J. A.: An analysis of ozonesonde data for the lower stratosphere: Recommendations for testing models, J. Geophys. Res., 104, 16151-16170, 1999.

Mote, P. W., Rosenlof, K. H., McIntyre, M. E., et al.: An atmospheric tape recorder: The imprint of tropical tropopause temperatures on stratospheric water vapor, J . Geophys. Res., 101(D2), 3989-4006, 1996.

Newchurch, M. J., Ayoub, M. A., Oltmans, S., Johnson, B., and Schmidlin, F. J.: Vertical distribution of ozone at four sites in the United States, J. Geophys. Res., 108, 4031, doi:10.1029/2002JD002059, 2003.

Pan, L., Solomon, S., Randel, W., Lamarque, J., Hess, P., Gille, J., Chiou, E., and McCormick, P.: Hemispheric asymmetries and seasonal variations of the lowermost stratospheric water vapor and ozone derived from SAGE II data, J. Geophys. Res., 102(D23), 28177-28184, 1997.

Pan, L. L., Hintsa, E. J., Stone, E. M., Weinstock, E., and Randel, W. J.: Seasonal cycle of water vapor and saturation mixing ratio in the extratropical lowermost stratosphere, J. Geophys. Res., 105, 26519-26530, 2000.

Pan, L. L., Randel, W. J., Gary, B. L., Mahoney, M. J., and Hintsa, E. J.: Definitions and sharpness of the extratropical tropopause: A trace gas perspective, J. Geophys. Res., 109, D23103, doi:10.1029/2004JD004982, 2004.

Petzoldt, K., Naujokat, B., and Neugebohren, K.: Correlation between stratospheric temperature, total ozone, and tropospheric weather systems, Geophys. Res. Lett., 21, 1203-1206, 1994.

Randel, W. J., Wu, F., Gettleman, A., Russell III, J. M., Zawodny, J. M., and Oltmans, S.: Seasonal variation of water vapor in the lower stratosphere observed in Halogen Occultation Experiment data, J. Geophys. Res., 106(D3), 14313-14325, 2001.

Randel, W. J., Seidel, D. J., and Pan, L. L.: Observational characteristics of double tropopauses, J. Geophys. Res., 112, D07309, doi:10.1029/2006JD007904, 2007.

Reed, R.: A study of a characteristic type of upper-level frontogenesis, J. Meteorol., 12, 226-237, 1955.

Rosenlof, K. H., Tuck, A. F., Kelly, K. K., Russell III, J. M., and McCormick, M. P.: Hemispheric asymmetries in water vapor and inferences about transport on the lower stratosphere, J. Geophys. Res., 102(D11), 13213-13234, 1997.

Russell, J. M., Gordley, L. L., Park, J. H., et al.: The halogen occultation experiment, J. Geophys. Res., 98, 10777-10797, 1993. 
Schubert, S. D. and Munteanu, M. J.: An analysis of tropopause pressure and total ozone correlations, Mon. Weather Rev., 116, 569-582, 1988.

Seidel, D. J., Ross, R. J., Angell, J. K., and Reid, G. C.: Climatological characteristics of the tropical tropopause as revealed by radiosondes, J. Geophys. Res., 106(D8), 7857-7878, 2001.

Seidel, D. J. and Randel, W. J.: Recent widening of the tropical belt: Evidence from tropopause observations, J. Geophys. Res., 112, D20113, doi:10.1029/2007JD008861, 2007.

Shalamyanskiy, A. M. and Romashkina, A. K.: Distribution and variation in the total ozone concentration in various air masses, Izv. Acad. Sci. USSR, Atmos. Oceanic Phys., 16, 931-937, 1980.

Shapiro, M. A.: Further evidence of the mesoscale and turbulent structure of upper level jet stream-frontal zone systems, Mon. Weather Rev., 106, 1100-1111, 1978.

Shapiro, M. A.: Turbulent mixing within tropopause folds as a mechanism for the exchange of chemical constituents between the stratosphere and troposphere, J. Atmos. Sci., 37, 994-1004, 1980.

Shapiro, M. A., Krueger, A. J., and Kennedy, P. J.: Nowcasting the position and intensity of jet streams using a satellite-borne Total Ozone Mapping Spectrometer, Nowcasting, Academic Press, San Diego, CA, 137-145, 1982.

Shapiro, M. A.: Dropwinsonde observations of an Icelandic low and a Greenland mountain-lee wave, Mon. Weather Rev., 113, 680-683, 1985
Sparling, L. C.: Statistical perspectives on stratospheric transport, Rev. Geophys., 38(3), 417-436, 2000.

Staehelin, J., Harris, N. R. P., Appenzeller, C., and Eberhard, J.: Ozone trends: A review, Rev. Geophys., 39, 231-290, 2001.

Steinbrecht, W., Claude, H., Köhler, U., and Hoinka, K. P.: Correlations between tropopause height and total ozone: Implications for long-term changes, J. Geophys. Res., 103, 19183-19192, 1998.

Taha, G., Thomason, L. W., and Burton, S. P.: Comparison of Stratospheric Aerosol and Gas Experiment (SAGE) II version 6.2 water vapor with balloon-borne and spacebased measurements, J. Geophy. Res., 109, D18313, doi:10.1029/2004JD004859, 2004.

Thomason, L. W., Burton, S. P., Iyer, N., Zawodny, J. M., and Anderson, J. M.: A revised water vapor product for the Stratospheric Aerosol and Gas Experiment (SAGE) II version 6.2 data set, J. Geophy. Res., 109, D06312, doi:10.1029/2003JD004465, 2004.

Varotsos, C., Cartalis, C., Vlamakis, A., Tzanis, C., Keramitsoglou, I.: The long-term coupling between column ozone and tropopause properties. J. Climate, 17, 3843-3854, 2004.

Wang, H. J., Cunnold, D. M., Thomason, L. W., Zawodny, J. M., and Bodeker, G. E.: Assessment of SAGE version 6.1 ozone data quality, J. Geophy. Res., 107, 4691, doi:10.1029/2002JD002418, 2002.

WMO: SPARC/IOC/GAW Assessment of trends in the vertical distribution of ozone: 1998, Ozone Research and Monitoring Project, Rep. 43, 289 pp, 1998. 